\title{
Pintura post-fotografía. Panorama y cuadro de acercamiento
}

\author{
Painting post-photo. Outlook and table of approaching
}

$<$ Resumen>

La invención de la fotografía no sólo establece una nueva relación entre el hombre y la realidad, sino también, modifica el estado del arte, acostumbrado hasta entonces a la representación figurativa de los acontecimientos. El proceso de transformación iniciado por los Impresionistas, hacia finales del siglo xix, seguirá en evolución permanente durante la primera mitad del siglo xx, período en que el arte finalmente establecerá el camino hacia la abstracción, despojándose de la transcripción literal de una realidad que ahora puede ser captada e inmortalizada por la fotografía.

$<$ Abstract $>$

The invention of photography not only establishes a new relationship between man and reality, but it also amends the state of the art, until then accustomed to the figurative representation of events. The transformation process initiated by the Impressionists, towards the end of the nineteenth century will remain in permanent evolution during the first half of the twentieth century a period in which art will eventually set the path to abstraction, from which the verbatim transcript of a reality now can be captured and immortalized by the photograph.

<PALABRAS CLAVE>

FOTOGRAFÍA / ARTE / ISMOS / PINTURA / ARQU I TECTURA

\section{<KEYWORDS}

PHOTOGRAPHY / ART / ISMS / PAINT ING /

ARCHITECTURE

\section{I ntroducción}

La caverna, sus dibujos interiores y la piel que cubre al hombre primitivo, el templo griego, un vaso helénico, el palacio renacentista y su pintura, la letra gótica, las ilustraciones de un libro y la catedral medieval, el arte de un juglar. Todas son consecuentes y expresan al hombre de su época.

En el futuro los ismos constituirán un solo paquete y en la historia de la Arquitectura se verá como una época en que el hormigón, el acero y el vidrio buscaban su propia expresión.

Habrá otros puntos de vista cuando nuestro presente sea un pasado remoto, entonces se harán lecturas que no imaginamos ahora.

Hoy en una microvisión agrupamos a Sant'Elia con Marinetti y D'Annunzio a Schwitters con Breton o Freud, a Guimard con Mucha y Tifanny. Nos acomoda partir de la pintura a la arquitectura, de Mondrian a Ritveld, del Cubismo a Le Corbusier, pero, llega un momento en que la ecuación se invierte. El deconstructivismo (término filosófico) que se origina en la arquitectura, pasa a otros campos. El ejemplo más patético es el de la moda deconstructivista, Kawakubo diseña vestidos imperfectos, con agujeros produciendo deformaciones con acolchados en que la figura humana aparece monstruosa.

Lo cierto es que tomamos conciencia que el arte, después de Marx, está regulado por el mercado como una mercancía. Incluso, cuando ha tratado de negarlo, en el realismo socialista el cliente es el mercado.

\section{Acercamiento a los I smos}

Es sorprendente cómo un invento puede influir tanto en campos que aparentemente son absolutamente ajenos a su área de influencia directa. Nos referimos a la fotografía quién se desplaza y camina naturalmente, dialogando con el cine, entrando a nuestros hogares a través de la televisión, poniendo en negativo nuestros huesos a través de los rayos $\mathrm{X}$ o registrando extensiones geográficas. 
Que influya sobre la arquitectura o la moda nos parece una cosa más compleja, pero ya veremos cómo esto se produce.

La fotografía, que etimológicamente significa "escritura de luz», inventada por Louis Daguerre ${ }^{1}$ en colaboración con JosephNicéphore Niépce², al mismo tiempo que Talbot $^{3}$ hacía descubrimientos similares en Londres, fue rechazada en un comienzo, pues su superficie pulida producía «un resplandor ofensivo a la vista». Una publicación alemana ${ }^{4}$ la combatió como una blasfemia: «Dios creó al hombre a su imagen y semejanza y ninguna máquina hecha por el hombre puede fijar la imagen».

Había llegado el momento de inventar esta máquina que se convertiría en una maldición para los pintores y para la pintura, que había testimoniado el quehacer humano desde tiempos de las cavernas, que había dejado en los muros egipcios, en los jarrones griegos y en las iglesias medievales el retrato del hombre. La pintura perdía ahora vigencia, ya que la realidad podía registrase con este nuevo artefacto, así que para los artistas este invento significó una importante pérdida, pero para el público en general fue una ganancia, pues cualquier hijo de vecino podía ser retratado, un privilegio hasta entonces reservado exclusivamente para personajes de alcurnia. En el mismo instante que se produce una democratización de la imagen, la pintura pierde su rol testimonial, ya no necesita registrar la realidad, puede ordenarla a su manera (Cézanne), cambiar sus colores (Gauguin), exagerar sus rasgos (Van Gogh), o hacer que los colores se fundan en la retina (Seurat). En un principio el espectador no podrá comprender la intención del autor, por lo cual será necesario enunciar los propósitos de su arte, naciendo de este modo los manifiestos. Documentos en que los artistas explicaran sus proposiciones a los espectadores que continúan con los hábitos visuales forjados desde el renacimiento. Aparece como profética una frase de Leonardo da Vinci «la pintura es una cosa mental».

Más que la técnica lo que ahora interesa es el concepto. No es una casualidad que Walter Gropius haya contratado como profesores, para las iniciación de la Bauhaus de Weimar, solo a maestros pintores, puesto que eran

Nicéphore Niépce. Vista desde la ventana en Le Gras (1826), primera fotografía permantente exitosa. Capturada con betún tratado al óleo en $20 \times 25 \mathrm{~cm}$, luego de una exposición de 8 horas (Fuente: Rebecca A. Moss).

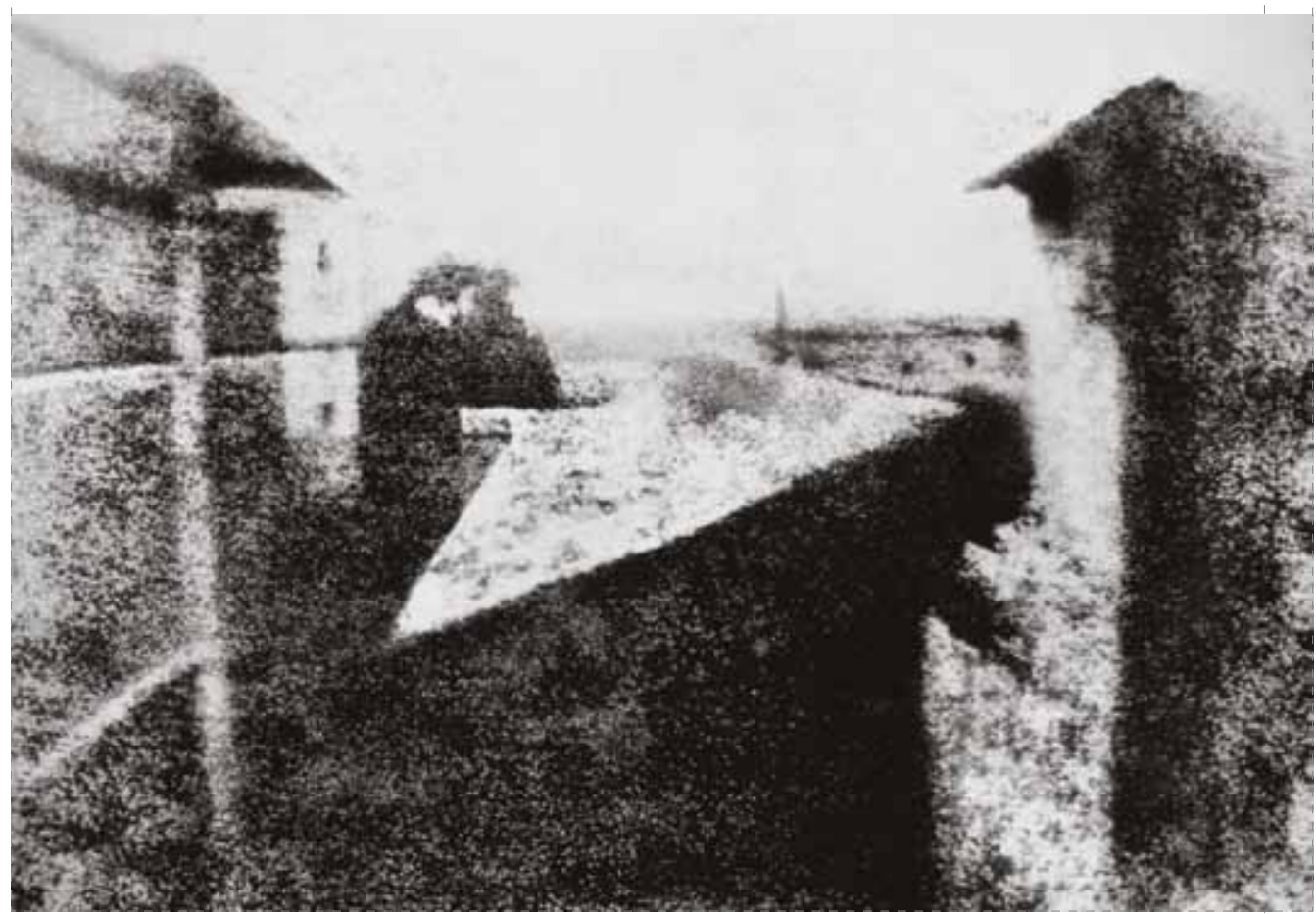

los innovadores del momento. La pintura comenzará a buscar su propia expresión por los más diversos caminos y nacerán ismos, de distinta extensión y distinta preocupación con parámetros de acción que al agotarse, darán paso a otros ismos, o que engendran un ismo contrario. La preocupación no está referida a la perfección de la técnica o del estilo, más importante que las manos será la cabeza del pintor. Esta idea se irá afirmando en el tiempo, hasta el extremo de que ya ni siquiera será necesaria la ejecución de la obra, bastará con pensarla, planearla por escrito o gráficamente, esto se llamará «Arte Conceptual». Para llegar a esto la pintura tendrá que pasar por muchas etapas y los pintores concebir expresiones no imaginadas como las de la pintura «no retiniana» como la que sugiere el francés Marcel Duchamp. En tal contexto, haremos aquí referencia a tres ismos, diferentes en expresión y extensión: Impresionismo, Cubismo y Fauvismo. Los tres con una extensión, un carácter y un peso distinto, los tres carentes de manifiestos, pero con el común denominador de romper con los hábitos visuales del espectador.

\section{Impresionismo}

Los pintores impresionistas, se distancian de los grandes cuadros históricos, realizados a partir de modelos vivos iluminados convencionalmente que posaban inmóviles. Ellos salieron al aire libre, en busca de la luz y sus variaciones, tratan de captar el momento con pinceladas cortas y ligeras, concibieron la perspectiva como un bulto sin la rigurosidad y rigidez de los principios geométricos del renacimiento. Este abandono del taller, ha sido posible gracias a la invención de la pintura industrial en París, pues hasta entonces, los pintores debían preparar personalmente los colores, usando distintos pigmentos.

Todo lo nuevo produce rechazo, en todos los campos, como sucedió con el vals, catalogado de baile escandaloso en el momento de su aparición. La crítica en París, en la primera exposición de grupo impresionista autodenominado como «Sociedad anónima de pintores, escultores y grabadores», realizada en el taller del fotógrafo Gaspar Félix «Nadar», en 1874, fue lapidaria. Los contemporáneos

(1787-1851) Pintor y decorador teatral francés.

(1755-1833) Terrateniente, químico, litógrafo y científico francés. «Punto de vista desde la ventana de Gras», es reconocida como la primera fotografía creada por él en el año 1826.

(1800-1877) Científico y filólogo Inglés, uno de los pioneros en el campo de la fotografía.

4 Der Leipziger Stadtanzeiger. 
Henri Matisse, La Danza (1910). Museo del Hermitage, San Petersburgo, Rusia.

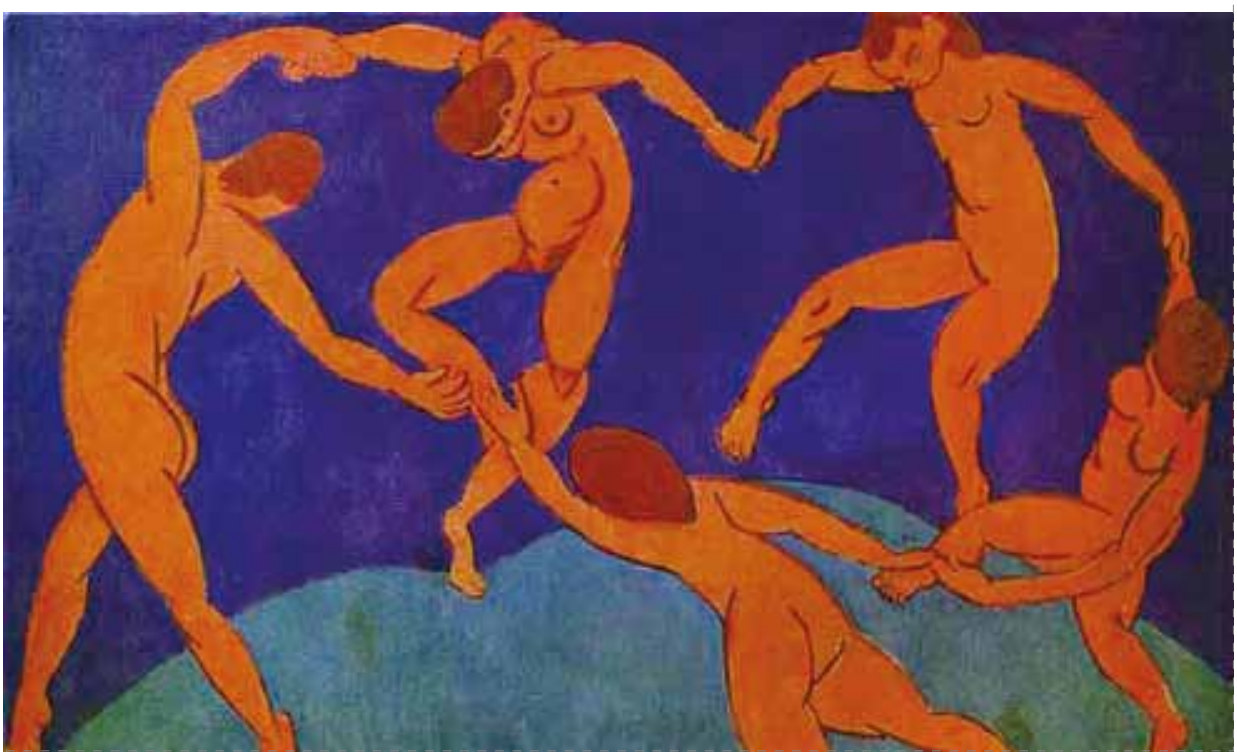

al nacimiento del impresionismo, no podían ver esa expresión como algo serio ni mucho menos elaborado. Eran unos cuadros

demasiado pequeños, pintados con urgencia, con apariencia de bocetos o apuntes para algo definitivo.

\section{Cub i smo}

La palabra vanguardia, un término militar que designa a los que van adelante, es bastante vacía en arte si no se visualiza en imágenes. D.H. Khanweiler en su estudio «Der Weg Zum Kubismus» ${ }^{5}$ señala al cuadro "Les Demoiselles d'Avignon» de Pablo Picasso como la obra que permite el nacimiento del cubismo. Es imposible saber qué pasaba entonces por la cabeza del pintor. Siempre se menciona como referencia directa en la obra de Picasso expresiones de arte africano y la pintura de Paul Cézanne ${ }^{6}$, sin embargo a diferencia de este último, Picasso era un superdotado, le costaba dibujar mal y vio en las estatuillas africanas una vía de aproximación al feísmo, un acercamiento a una visión anti-plástica de tal nivel que se convirtió en algo imposible de mostrar.

Tanto Picasso como Braque reciben las influencias de Cézanne, quien por entonces postulaba reducir la naturaleza a las figuras geométricas básicas. Poco a poco, otros pintores adhieren al cubismo, Juan Gris, Marcoussis, Metzinger, Gleizes, sumándose también dos escultores; el rumano Brancusi y el ruso Archipenko, sin embargo subsiste el rechazo frente a este nuevo movimiento artístico. Sin embargo Pablo Picasso cuenta con un par de mecenas norteamericanos millonarios, los hermanos Leo y Gertrudis Stein, y el magnate ruso Sergei Shchukin ${ }^{7}$, que le permiten seguir con su trabajo y experimentación.

En el año 1910 finaliza el cubismo-cúbico pero los historiadores del arte insisten en prolongar este término en dos etapas fundamentales; cubismo analítico y cubismo sintético. Obras a modo de retratos acristalados recibieron el título de cubismo analítico, mientras que el cubismo sintético se caracterizará por incorporar palabras, frases y/u objetos pegados en el propio cuadro. Lamentablemente el cubismo ha pasado a ser lo que repiten y escriben los historiadores del arte, incorporando incluso a algunos músicos al movimiento como Satié y Stravinsky.

\section{Fauvismo}

"Donatello entre las fieras» fue la frase utilizada por Louis Vauxcelles en 1905 al comentar el Salón de Otoño. La Fieras eran: Vlaminck, Marquet, Derain, Dufy, Manguin, Camión, Van Dongen y Matisse, este último el más difundido por razones publicitarias y comerciales. Matisse, al igual que Picasso contó con el mecenazgo de los Hermanos Stein.

Morosov, un rico coleccionista ruso lo invitó a Moscú para que instalara personalmente "La Danza» y «La Música» y compró una gran cantidad de sus obras, también expuso en Nueva York y en la Galería Steiglitz. Henry Matisse, es mencionado como el
Paul Sérusier El Talisman (1888). Museo d’Orsay, París, Francia.

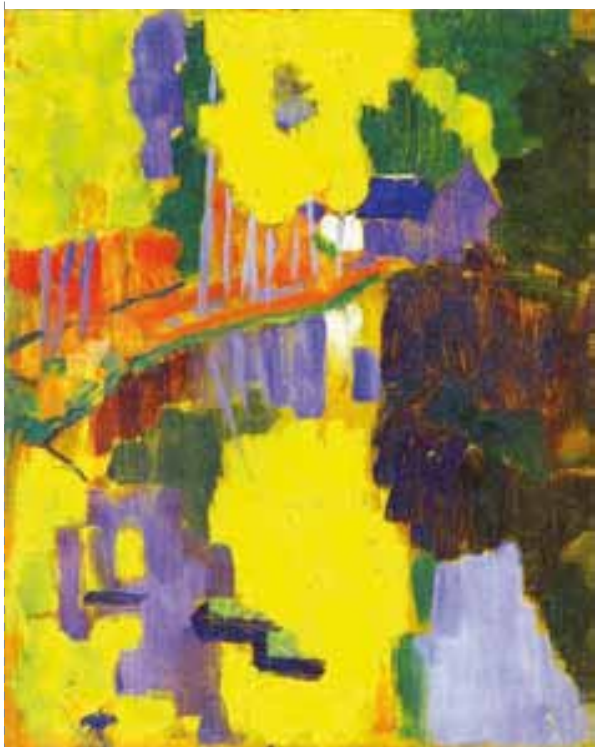

más destacado y característico artista de los Fauves, cuya característica es el color violento en un dibujo poco riguroso, antinatural, que no respeta la realidad, sin perspectiva ni sombras.

El Fauvismo se desarrolla entre los años 1904 y 1908, sus integrantes carecen de un programa común que los una, no poseen un manifiesto. Sus temas son retratos, naturalezas muertas, paisajes o interiores. Ignora la perspectiva, el volumen, el claro oscuro, esquematizando las figuras como las expresiones que los pueblos primitivos tienen. En esta línea se puede mencionar como antecedente del Fauve a los $\mathrm{Nabis}^{8}$, quienes siguieron los consejos que Gauguin le dio a Paul Sérusier ${ }^{9}$ : "Si ves amarillo, elige el amarillo más estridente que tengas en la paleta y aplícalo al cuadro», con esta idea él pintó la tapa de una caja de tabaco, que se constituyó en el «Talismán» del grupo.

5 D.H. Kahnweiler, 1884-1979. Alemán, que en su juventud abrió una galería en París. Sensible a las exploraciones formales de sus contemporáneos, fue capaz de identificar las tendencias que emergían.

1839-1906. Pintor francés que exploró la transición del arte del siglo xix hacia uno "moderno».

1854-1936. Empresario textil ruso que se convirtió en coleccionista de arte.

Del hebreo: profeta. Grupo de artistas franceses.

9 1864-1927. Pintor francés asociado a los Nabís. 